\title{
Öğrenme Eğrisinde Median Lob Varlığının Robot Yardımlı Radikal Prostatektomide Onkolojik ve Fonksiyonel Sonuçlar Üzerine Etkisi
}

\author{
The Effect of Median Lobe Presence on Oncologic and Functional Outcomes in Robot \\ Assisted Radical Prostatectomy in the Learning Curve
}

\author{
İbrahim Karabulut, Fatih Kürșat Yılmazel, Onur Ceylan
}

SBÜ Erzurum Eğitim Araștırma Hastanesi Üroloji Servisi Erzurum

Geliş tarihi (Submitted): 12.12.2019

Kabul tarihi (Accepted): 03.02.2020

Yazışma / Correspondence

İbrahim Karabulut

SBÜ Erzurum Eğitim Araştırma

Hastanesi Üroloji Servisi Erzurum

Tel: 05054908194

E-mail: karabulutibrahim36@gmail.com

\section{ORCID}

İ.K. 0000-0001-6766-0191

F.K.Y. 0000-0001-8744-5317

O.C. $0000-0001-7025-0521$

\section{(i) (8)}

Bu eser Creative Commons AttfGayriTicari 4.0 Uluslararası Lisansı ile lisanslanmıștır.

\section{Özet}

Amaç: Robot yardımlı laparaskopik radikal prostatektomi (RALP), öğrenme eğrisinde median lob (ML) varlığının perioperatif, onkolojik ve fonksiyonel sonuçlar üzerine etkisini araştırmayı amaçladık.

Gereç ve Yöntemler: Kliniğimizde Temmuz 2018 ile Ekim 2019 tarihleri arasında RALP uygulanan 38 ardışık hastayı analiz ettik. Hastalara ilk öğrenme eğrisinde ki aynı cerrahi ekip tarafindan opere edildi. RARP sırasında belirlenen bir ML varlığına veya yokluğuna göre iki gruba ayrıldı. Perioperatif, onkolojik ve fonksiyonel sonuçlar gruplar arasında karşılaştırıldı.

Bulgular: Çalışmaya dahil edilen hastaların 10 (\% 26,3)'un da bir ML varlığı tespit edildi. Her iki grupta da prostat spesifik antijen (PSA), vücut kitle indeksi(BMI), hastanede kalıs süresi, perioperatif ve postoperatif komplikasyon oranları benzerdi $(\mathrm{p}<0,01)$. Cerrahi sınır pozitifliği oranı ise ML grubunda \%20 (2/10) iken ML'suz grupta \%10,7 (3/28) olarak tespit edilidi. Gruplar arası sayısal farklar istatistiksel açıdan anlamlı bulunmadi $(\mathrm{p}<0,01)$. Aynı zaman da prostat volümü $(\mathrm{p}=0,008)$ ve tahmini kan kaybı da (TKK) $(\mathrm{p}=0,001)$ median loblu bulunan hastalar lehine anlamlı idi. Ortalama konsol süresi ML'lu hastalarda biraz daha fazla olmasına rağmen bu sayısal farklar istatistiksel açıdan anlamlı bulunmadi $(\mathrm{p}<0,01)$. Mesane boynu rekonstruksiyon oranları ML grubunda $\% 100$

\section{Abstract}

Objective: We aimed to investigate the effect of the presence of median lobe (ML) in the learning curve on perioperative, oncologic and functional outcomes.

Material and Methods: We analyzed 38 consecutive patients undergoing RALP in our clinic between July 2017 and October 2019. Patients were operated by the same surgical team on the first learning curve. They were analyzed in two groups according to the presence or absence of a ML determined during RARP. Perioperative, oncologic and functional results were compared between the groups.

Results: Prostatic ML was detected in 10 (26.3\%) of the patients included in the study. Prostate specific antigen (PSA), body mass index (BMI), length of hospital stay, perioperative and postoperative complication rates were similar in both groups $(\mathrm{p}<0.01)$. Surgical margin positivity rate was $20 \%(2 / 10)$ in the ML group and $10.7 \%(3 / 28)$ in the ML group. Numerical differences between the groups were not statistically significant $(p<0.01)$. Nevertheless, prostate volume $(\mathrm{p}=0.008)$ and estimated blood loss (TCC) $(\mathrm{p}=0.001)$ were significant in favor of patients with median lobes. Although the mean cantilever time was slightly higher in patients with ML, these numerical differences were not statistically significant ( $\mathrm{p}<0.01)$. Bladder neck reconstruction rates were $100 \%$ (100\%) in the ML group and 
(\%100) iken ML’suz grupta \%14 (4/28) olarak ölçüldü(p=0,001). ML olan ve olmayan hastalar arasinda kontinans oranları, kateter çıkarılmasından sonra 4. hafta da (\% 20 - \%35) , 12. hafta da (\% 70 -\% 64,2) ve 24 . hafta da (\% 90 -\% 89,2) da benzer olup tüm zamanlarda istatistiksel açıdan anlamlı fark gözlenmedi.

Sonuç: Öğrenme eğrisinde RALP’nin yüksek cerrahi tecrübesi bulunmayan merkezlerde de zorlu vakalarda da güvenli ve etkili bir şekilde uygulanabileceğini düşünmekteyiz. Bizim başlangıç serimizde karşılaştığımız ML'lu vakaların ML'suz vakalarla karşılaştırıldığında onkolojik, fonksiyonel sonuçları ve komplikasyon oranları$\mathrm{n} 1$ literatür ile uyumlu olduğunu tespit ettik.

Anahtar Kelimeler: Robot yardımlı radikal prostatektomi, öğrenme eğrisi, median lob
$14 \%(4 / 28)$ in the ML-free group $(\mathrm{p}=0.001)$. Continence rates between patients with and without ML were at 4 weeks (20\% to $35 \%$ ) after catheter removal, at 12 weeks (70\% to $64.2 \%$ ) and at 24 weeks (90\% to $89.2 \%)$. ) and no statistically significant difference was observed at all times.

Conclusion: Learning curve, we think that RALP can be applied safely and effectively in challenging cases in centers without high surgical experience. When we compared the oncologic, functional and complication rates of patients without ML in our initial series, we obtained results consistent with the literature.

Keyword: Robot-assisted radical prostatectomy, learning curve, median lobe

\section{GíRiş}

Prostat spesifik antijen (PSA) testinin yaygin bir şekilde kullanılmasıyla, lokalize prostat kanseri(LPca) insidansı önemli ölçüde artmıştır(1). Lokalize prostat kanseri tedavisinde radikal prostatektomi uygun hasta grubunda iyi bir seçenektir. Radikal prostatektomi; açık, laparoskopik ve robot yardımlı laparoskopik olmak üzere üç farklı şekilde yapılabilmektedir. LPca tedavisinde robot yardımlı laparoskopik radikal prostatektomi (RALP) uzun zamandan beri etkinliği kanıtlanmış minimal invaziv bir tedavi yaklaşımıdır(2). Robot yardımlı radikal prostatektomi LPca hastaları için cazip bir tedavi seçeneği olarak ortaya çımıştır. RALP LPca hastalarında kabul edilebilir onkolojik ve fonksiyonel sonuçlar sağlarken, minimal invaziv bir yaklaşımın faydalarını da sunmaktadır(3). Tüm bunların sonucu olarak RALP, hızlı bir şekilde açık radikal prostatektominin yerini almaktadır.(4) RALP'ın cerrahi tekniği günümüzde belli bir standarda ulaşmıştır ve büyük vaka serileri bu prosedürün fizibilitesini, güvenliği ve tekrarlanabilirliğini onaylamaktadır(5).

Median prostat lobu (ML) mesane boynunun anatomisini bozabilir ve bu da mesane boynu diseksiyonunu daha da zorlaştırabilir. Bir ML'un varlığ 1 , prostat ile mesane boynu arasındaki düzlemi gizleyerek bu diseksiyonu özellikle de ilk öğrenme eğrisi sırasında teknik olarak zorlu hale getirebilir. Bu durum, mesane boynundaki pozitif cerrahi sınır (PCS) oranları, tahmini kan kaybı (TKK) ve ameliyat süresi gibi postoperatif ve perioperatif sonuçları ML varlığından dolayı etkileyebilir.
Biz bu çalışmamızda, RALP’nin ilk öğrenme eğrisi peryodunda, ML varlığının perioperatif, onkolojik ve fonksiyonel sonuçlara etkisini değerlendirmeyi amaçladik.

\section{MATERYAL VE METOD}

Çalışma öncesi yerel etik kuruldan onay alındı. Kliniğimizde Temmuz 2018 ile Ekim 2019 tarihleri arasında RALP uygulanan 38 ardışı hastayı analiz ettik. Hastalar, RARP sırasında cerrah tarafindan tanımlanan bir ML'nun varlığına veya yokluğuna göre iki grupta ayrılarak değerlendirildi.

İdrar kontinansı, üriner kateterin çıkarılmasından sonra 4, 12 ve 24 . haftalarda uygulanan, onaylanmıs bir anket olan Expanded Prostat Cancer Index Composite (EPIC) (6) ile değerlendirildi. Kontinansın tanımlaması, hastaların anketin: "Son 4 hafta boyunca idrar kaçağını kontrol etmek için genellikle günde kaç ped ya da yetişkin bezi kullandınız mı?” sorusuna verdikleri cevaplara dayanıyordu. Kontinans, " ped kullanmadım " cevabı olarak tanımlandı.

Yaş, vücut kitle indeksi(BMI), preoperatif PSA, prostat büyüklügü, cerrahi sınır durumu, tahmini kan kaybı (TKK), toplam operasyon süresi, hastanede kalış süresi, üretral sonda alınma süresi, intraoperatif ve postoperatif komplikasyonlar gibi veriler retrospektif olarak topland. Elde edilen verilerin istatistiksel açıdan anlamlı olup olmadıkları değerlendirildi.

\section{Cerrahi Teknik ve Perioperatif Yönetim}

Tüm RALP'ler, 4 kollu bir da Vinci Xi Cerrahi Sistem (Intuitive Surgical, Sunnyvale, CA) kullanılarak transperitoneal olarak gerçekleştirildi. Mesane boynu 
diseksiyonu sırasında 30 derecelik aşağ 1 bakan lens kullanıldı.

Cerrahi ekibin tamamı Sağlik Bilimleri Üniversitesi Bakırköy Sadi Konuk Eğitim ve Araştırma Hastanesi Üroloji Kliniğinde 12 haftalık robotik cerrahi eğitimi sonrası kliniğimizde RALP operasyonlarına başladı. $\mathrm{Bu}$ sayede intraoperatif median lop varlığını değerlendirmeye ve ML varlığın da operasyonu yönetmeye hâkimdi. ML varlığını tespitinde intraoperatif değerlendirme temel alındı. Bu değerlendirme; foley kateterine traksiyon uygulandığında balonun kontralateral sapması gibi anatomik işaretlere veya cerrahi manevralara dayanan intraoperatif bir tanıdı. Arka mesane boynu ile prostat birleşme yerini bulmak için median lobdan sutur geçildi ve dördüncü kol kullanılarak ML'lar yukarı doğru çekildi(7). Bu noktada, üreter orifisleri sıklıkla büyük bir lobun sınırlarına yakın olmasından dolayı dikkatlice incelendi. Gerekli görüldügünde, büyük ML'larda, üreteral orifisleri anastomoz hattından uzaklaştırmak için mesane boynu rekonstrüksiyonu yapildı.

Kural olarak, hastalar ameliyat sonrası 7. günde, kateter çıkarılmadan önce sistografi yapılarak kaçak kontrolünden sonra taburcu edildi. Bir idrar kaçağ tespit edildiğinde, üretral kateter 5 ila 7 gün daha tutuldu.

\section{ISTATISTIKSEL METOD}

Veriler değerlendirmek için Windows SPSS sürüm18.0 (SPSS Inc., Şikago, IL, ABD) kullanıldı. WerollMann-Whitney-U testine göre gruplar arasında sürekli değişkenlerin karşılaştırılması. Nominal değişkenler, Pearson $\chi 2$ testiyle analiz edildi. $\mathrm{P}<0,05$ değerleri istatistiksel olarak anlamlı kabul edildi.

\section{SONUÇLAR}

Robot yardımlı laparoskopik radikal prostatektomi uygulanan 38 hasta çalışmamıza dahil edildi. Çalışmaya dahil edilen hastaların 10 'un da (\% 26,3) ML varlığı tespit edilirken, 28 'in de $(\% 73,6) \mathrm{ML}$ izlenmedi. Preoperatif parametrelerin değerlendirilmesinde yaş, body mass indeks (BMI) ve PSA değerleri arasında istatistiksel açıdan anlamlı bir fark gözlenmedi $(\mathrm{p}<0,01)$. Prostat volümü ML $90 \pm 8$ gr ilen ML’suz grupta $68 \pm 3$ gr olarak ölçüldü. Aradaki fark ML grubu lehine is- tatistiksel olarak anlamlı derecede büyüktü $(\mathrm{p}=0,008)$ (Tablo 1).

İntraoperatif verilerin değerlendirilmesinde; konsol süresi ML grubunda $202 \pm 6 \mathrm{dk}$ iken diğer grupta $193 \pm 2$ dk olarak tespit edildi. Buna karşın tahmini kan kaybı ML grubunda $138 \pm 8 \mathrm{cc}$ iken ML'suz grupta $103 \pm 2$ cc ölçüldü( $\mathrm{p}=0,001)$. Mesane boynu rekonstruksiyon oranları ML grubunda \%100 (\%100) iken ML’suz grupta \%14(4/28) olarak ölçüldü( $\mathrm{p}=0,001)$.

Postoperatif verilerin değerlendirilmesinde; üretral stent alma zamanı ML grupta 7,6 $\pm 0,5$ gün iken ML'suz grupta $6,3 \pm 0,2$ gün olarak ölçüldü $(\mathrm{p}=0,01)$. Gruplar arasında oluşan sayısal farklar istatistiksel olarak ML grubu lehine anlamlı idi(Tablo 2). Hastanede kalış süresi ML grubunda 6,8 $\pm 0,4$ gün iken ML’suz grupta $6,3 \pm 0,1$ gün olarak ölçüldü. Cerrahi sınır pozitifliği ise ML grubunda \%20 (2/10) iken ML'suz grupta \%10,7 (3/28) olarak tespit edildi. Gruplar arası sayısal farklar istatistiksel açıdan anlamlı bulunmadı( $\mathrm{p}<0,05)$ (Tablo 2).

Uzun dönem kontinans takiplerinde tam kontinans oranları sirası ile 1. 3. ve 6. ayda ML grubunda \%20 (4/20), \%70 (7/10) , \%90 (9/10) iken ML’suz grupta $\% 35(10 / 28), \% 64,2(18 / 28), \% 89,2(25 / 28)$ olarak tespit edildi. Gruplar arasında tüm zamanlarda istatistiksel açıdan anlamlı bir fark gözlenmedi $(\mathrm{P}<0,05)$ (Tablo 3).

Perioperatif ve postoperatif komplikasyon oranları ML grubunda \%20(2/10), ML'suz grupta \%10,7 (3/28) olarak ölçüldü. Gruplar arası fark istatistiksel açıdan anlamsız idi $(\mathrm{p}=0,59)$.

\section{TARTIŞMA}

RALP hakkında onkolojik ve fonksiyonel sonuçlar bildiren geniş seriler yayınlanmıştır $(3,8)$ ve lokalize prostat kanseri olan hastalar için RALP günümüzde öncelikle tercih edilen bir tedavi seçeneği haline gelmiştir. Bunun bir sonucu olarak üroloji uzmanları zorlu vakalarla ( obez hastalar, büyük prostatlar, önceki prostat ameliyatları ve ML vs.) kliniklerinde daha sık karşılaşmaktadır.

Literatürde ML ile ilgili ilk karşılaştırmalı çalışma Jenkins ve arkadaşları (9) tarafından yapılmıştır. Yaptıkları küçük sayıda hasta içeren çalışmada $(n=58)$ 
Tablo 1. Preoperatif Hasta Karakteristikleri

\begin{tabular}{lccc}
\hline Tüm Hastalar (n=38) & $\begin{array}{c}\text { Grup I (Median Lob) } \\
\mathbf{n = 1 0}\end{array}$ & $\begin{array}{c}\text { Grup II (Median Lobsuz) } \\
\mathbf{n = 2 8}\end{array}$ & p (value) \\
\hline Age (years) & $62 \pm 4$ & $61 \pm 5$ & 0,56 \\
\hline BMI $(\mathrm{kg} / \mathrm{m} 2)$ & $26 \pm 2$ & $25 \pm 2$ & 0,76 \\
\hline Serum PSA (ng/mL) & $9 \pm 0,9$ & $11 \pm 2,6$ & 0,54 \\
\hline Prostate volume (cc) & $90 \pm 8$ & $68 \pm 3$ & $0,008^{*}$ \\
\hline
\end{tabular}

PSA: prostate-specific antigen; BMI: body mass index

SEM;Standart error of mean, Data were analyzed with Mann-Whitney-U test.

* $\mathrm{P}<0,05$

Tablo 2. Pireoperatif ve Postoperatif Hasta Karekteristikleri

\begin{tabular}{lccc}
\hline Tüm Hastalar (n=38) & $\begin{array}{c}\text { Grup I (Median Lob) } \\
\mathbf{n = 1 0}\end{array}$ & $\begin{array}{c}\text { Grup II (Median Lobsuz) } \\
\mathbf{n = 2 8}\end{array}$ & p (value) \\
\hline Konsol Süresi (dk) & $202 \pm 6$ & $193 \pm 2$ & 0,05 \\
\hline Tahmini Kanama Miktarı (ml) & $138 \pm 8$ & $103 \pm 2$ & $0,001^{*}$ \\
\hline Mesane Boynu Rekonstrusksiyonu & $10(\% 100)$ & $4(\% 14)$ & $0,001^{*}$ \\
\hline Hastanede Kalış süresi (gün) & $6,8 \pm 0,4$ & $6,3 \pm 0,1$ & 0,18 \\
\hline Üreteral Katater Alma Zamanı (gün) & $7,6 \pm 0,5$ & $6,3 \pm 0,2$ & $0,01^{*}$ \\
\hline Pozitif Cerrahi Sınır & $2(\% 20)$ & $3(\% 10,7)$ & 0,59 \\
\hline $\begin{array}{l}\text { Perioperatif, Postoperatif } \\
\text { Komplikasyon }\end{array}$ & $2(\% 20)$ & $3(510,7)$ & 0,59 \\
\hline \multirow{*}{*}{ P 005} & &
\end{tabular}

${ }^{\star} \mathrm{P}<0,05$

SEM;Standart error of mean, Data were analyzed with Mann-Whitney-U test.

Ki kare (chi-square) ile analiz yapild.

Tablo 3. Postoperatif Kontinans

\begin{tabular}{lccc}
\hline Tüm Hastalar (n=38) & $\begin{array}{c}\text { Grup I (Median Lob) } \\
\mathbf{n = 1 0}\end{array}$ & $\begin{array}{c}\text { Grup II (Median Lobsuz) } \\
\mathbf{n = 2 8}\end{array}$ & p (value) \\
\hline Üriner Kontinans 4. Hafta & 2 & 10 & 1 \\
\hline Üriner Kontinans 12. Hafta & 4 & 18 & 1 \\
\hline Üriner Kontinans 24. Hafta & 7 & 25 & 1 \\
\hline
\end{tabular}

Ki kare (chi-square) ile analiz yapıldı.

operasyon zamanı açısından ML hastalar ve kontrol grubu karşılaştırıldığında önemli bir fark bulunmamıştır. Jenkens'in (9) çalışmasında ML'lu hastalarda ortalama operasyon süresi $289 \mathrm{dk}$ iken, kontrol grubunda bu süre $274 \mathrm{dk}$ olarak ölçülmüştür. İki grup arasındaki bu sayısal fark istatistiksel açıdan anlamlı bulunmamıştır. Bu sonuçlar çalışılan hasta grubunun küçük olmasına bağlanabilir. Meeks ve arkadaşlarının (10) yaptığ çalışmada ise ML'lu hastalar ile kontrol grubu karşılaştırıldığında, ML'lu hastalarda operasyon süresinin yaklaşık $70 \mathrm{dk}$ daha uzun olduğu tespit edilmiştir. Sürede ki bu farkın ML’lu hastalarda mesane boynu arka kısmı ve seminal vezikül diseksiyonu ile mesane boynu rekonstruksiyonu için gerekli olduğunu vurgulamışlardır. Yine Zorn ve arkd.(11) yaptığı çalışmada prostat volümü ile operasyon süresi arasında ilişki bulunamamıştır. Bizim çalışmamızda da önceki çalışmalarla benzer şekilde ML’lu hastalar ile kontrol grubu kıyaslandığında ML'lu grup lehine uzun olduğunu ve bu farkın istatistiksel açıdan anlamlı olmadığını gözlemledik $(p=0,05)$. Bunda çalışma grubumuzun küçük olmasının ve literatüre kıyasla daha düşük volümlü prostatları içermesinin etkili olduğu kanaatindeyiz.

Jenkins ve arkadaşları (9) çalışmasında TKK karşılaştırmış ve her iki grupta istatistiksel açıdan anlamlı fark bulamamıştır. Coelho ve arkadaşları(12)'da benzer sonuçlar elde etmiştir. Buna karşın kontrol grubu 
ile kıyaslandığında kanama miktarının istatistiksel açıdan anlamlı olacak şekilde fazla olduğunu destekleyen çalışmalarda bulunmaktadır(10). Bizim çalışmamızda da ML'suz grup ile kiyaslandığında ML grubunda TKK istatistiksel açıdan anlamlı derecede yüksek olduğu gözlenmiştir ( $\mathrm{p}=0,001)$. Bunda etkili olan faktörün $\mathrm{ML}$ grubunda prostat volümünün fazla olması ve mesane posterior duvarı ve seminal vezikal diseksiyonun zorluğu olabileceği kanaatindeyiz.

Pozitif cerrahi sınır oranları (PCS) Jenkens ve arkadaşlarının (9) yaptığı çalışmada ML’lu hastalarda \%10 iken ML’suz hastalarda \%21 olarak tespit edilmiştir. Aradaki bu fark istatistiksel olarak anlamlı bulunmamıştır. Yine yapılan diğer çalışmalarda da benzer sonuçlar Coelho ve arkadaşları (12) tarafından bulunmuştur. Buna karşın Jung ve arkadaşlarının(13) çalışmasinda ise PCS oranları ML'suz hasta grubunda daha düşük bulunmuştur. Bizim çalışmamız da ise ML hasta grubu ile kontrol grubu karşılaştırıldığında, ML olan hastalarda PCS sayısal olarak daha az olduğu fakat bu farkın istatistiksel açıdan anlamlı olmadı̆̆ını tespit ettik $(p=0,59)$. Bunda etkili olan faktörün median lobun diseksiyonu esnasında sütür yardımı ile asılması ve daha geniş mesane eksizyonu olduğu kanaatindeyiz.

Daha önce yapılan çalışmalarda ML varlığının komplikasyon oranlarını etkilemediği gösterilmiştir. Huang ve arkadaşlarının (13) yaptığı çalışmada anastamoz darlığı, rektal yaralanma, üretral yaralanma, üriner sistem enfeksiyonu oranları ML'lu ve ML'suz hasta gruplarında benzer olduğu tespit edilmiştir. Benzer genel komplikasyon oranlarını Jenkins ve arkadaşları (9) tarafından raporlanmıştır(\%10,3 vs \%13,7). Bunlardan farklı olarak Jung ve arkadaşaları (14) komplikasyonları intraoperatif ve postoperatif olarak sinıflandırdı ve benzer sonuçlar gözlemlemişlerdir. Çalışmamızda ML'lu grupta 1 hastada medikal tedavi ile düzelen ileus (Clavien-Dindo 1) ve 1 hastada port yerinde kanama (Clavien-Dindo 3b), ML'suz grupta ise 2 hastada medikal tedavi ile düzelen ileus (Clavien-Dindo 1) ve 1 hasta port yerinde kanama (Clavien-Dindo 3b) gözlendi. Bizim çalışmamızda da intraoperatif ve postoperatif komplikasyonlar kıyaslandığında gruplar arasında istatistiksel açıdan anlamlı fark bulunmadı $(\mathrm{P}=0,59)$,
ML varlığının komplikasyonlar ile ilişkisi tespit edilmedi ve bu sonuçlar literatür ile uyumlu idi.

Huang ve arkadaşları (13) uzun dönem (24 aya kadar) üriner kontinans takiplerinde gruplar arasında herhangi bir istatistiksel farkın olmadığını tespit ettiler. Jenkins ve arkadaşları(9) farklı olarak operasyon sonrasi tam kontinans gelişinceye kadar geçen süreyi gruplar arasında karşılaştırdılar ve sonuçta ML'lu olan hastalarda tam kontinansın daha uzun sürede geliştiği fakat bu süre farkının istatistiksel açıdan anlamlı olmadığını tespit ettiler. Bununla birlikte aynı çalışmada mesane boynu rekonstruksiyon oranlarının ML'lu olan hasta grubunda istatistiksel açıdan anlamlı derecede yüksek olduğu tespit edilmiş. Coelho ve arkadaşlarının (12) çalışmasında ise erken ve geç dönem kontinans oranlarını karşılaştırmış ve iki grup arasında anlamlı bir fark bulunmamıştır. Yine benzer şekilde Coelho (12)'nun çalışmasında da mesane boynu rekonstruksiyon oranları ML'lu hasta grubunda daha yüksek rapor edilmiştir. Farklı bir çalışmalarda $(15,16)$ mesane boynu rekonstruksiyonu ile kontinansın kazanılma süresi arasında ilişki olduğunu tespit etmişlerdir. Bizim çalışmamızda da erken kontinans oranları oransal olarak daha yüksek iken ve geç kontinans oranları benzer bulundu. Ancak tüm zamanlarda farklar istatistiksel açıdan anlamlı değildi. Erken kontinansın kazanılmasında etkili olan faktörün ML bulanan hastalarda mesane boynunun rekonstrüksiyonuna olduğu kanaatindeyiz. Aynı zamanda bizim çalışmamızda mesane boynu rekonstrüksiyon oranları ML'lu hasta grubunda istatistiksel açıdan anlamlı derecede yüksek bulunmuştur $(\mathrm{P}=0,001)$. Bu sonuç literatür ile uyumlu idi.

Hastanede kalış süreleri literatüre kıyasla bizim çalışmamızda daha uzun olarak tespit edildi. Bunda etkili olan faktörün öğrenme eğrisinde başlangıç vakalarının olası komplikasyonlara karşı daha uzun süre takip edilmesine bağlı olduğunu düşünmekteyiz.

Bizim çalışmamız da bazı sınırlamalar mevcut olup bunlar; tarif ettiğimiz çalışma grubunun büyüklüğünün ML' lu erkekler için nispeten küçük olması, ML varlığının öznel olarak cerrahın bakış açısına göre değerlendirmesidir. Aynı zamanda hastaların preoperatif dönemde ML varlığı açısından görüntüleme yöntem- 
leri ile değerlendirilmemesi ve PCS oranları gruplar arasında benzer olmasına rağmen uzun süreli onkolojik sonuçların bulunmamasıdır.

\section{SONUÇ}

Son yıllarda Pasenda Konsensüs Paneli ML varlığ ${ }^{-}$ nı RALP'de zorlu vaka olarak değerlendirdi ve prosedürün deneyimli ellerde yapılması gerektiğini vurgulamaktadır. Bizim başlangıç serimizde karşılaştığımız ML’lu vakaların ML'suz hastalarla onkolojik sonuçları, fonksiyonel sonuçları ve komplikasyon oranları karşılaştırıldığında literatür ile uyumlu sonuçlar elde ettik. Sonuç olarak RALP’nin yüksek cerrahi tecrübesi bulunmayan merkezlerde zorlu vakalarda da güvenli ve etkili bir şekilde uygulanabileceğini düşünmekteyiz. Çalışmamızı destekleyen daha geniş seride prospektif çalışmalara ihtiyaç duyulmaktadır.

\section{REFERANSLAR}

1. Hayat HJ, Howlader N, Reichman ME, Edwards BK. Cancer statistics, trends, and multiple primary cancer analyses from the Surveillance, Epidemiology and End Results (SEER) Program. Oncologist 2007;12:20-37.

2. Cooperberg MR, Broering JM, Carroll PR (2010) Time trends and local variation in primary treatment of localized prostate cancer. J Clin Oncol 2010;28:1117-23.

3. Coelho RF, Chauhan S, Palmer KJ, et al. Robotic-assisted radical prostatectomy: A review of current outcomes. BJU Int 2009;104:1428-35.

4. Guru KA, Hussain A, Chandrasekhar R et al (2009) Current status of robot-assisted surgery in urology: a multi-national survey of 297 urologic surgeons.Can J Urol 2009;16:473641.

5. Binder J, Kramer W. Robotically-assisted laparoscopic radical prostatectomy. BJU Int 2001;87:408-10.

6. Wei JT, Dunn RL, Litwin MS, et al. Development and validation of the expanded prostate cancer index composite (EPIC) for comprehensive assessment of health-related quality of life in men with prostate cancer. Urology 2000;56: 899-905.

7. Sarle R, Tewari A, Hemal AK, Menon M. Robotic-assisted anatomic radical prostatectomy: technical difficulties due to a large median lobe. Urol Int 2005;74:92-4.

8. Ficarra V, Novara G, Artibani W, et al. Retropubic, laparoscopic, and robot-assisted radical prostatectomy. A systematic review and cumulative analysis of comparative studies. Eur Urol 2009;55:1037-63.
9. Jenkins LC, Nogueira M, Wilding GE et al (2008) Median lobe in robot-assisted radical prostatectomy: evaluation and management. Urology 2008;71:810-3.

10. Meeks JJ, Zhao L, Greco KA, Macejko A, Nadler RB (2009) Impact of prostate median lobe anatomy on robotic-assisted laparoscopic prostatectomy. Urology 2009;73:323-7.

11. Zorn KC, Orvieto MA, Mikhail AA, et al. Effect of prostate weight on operative and postoperative outcomes of roboticassisted laparoscopic prostatectomy. Urology 2007;69:3005.

12. Coelho RF, Chauhan S, Guglielmetti GB et al (2012) Does the presence of median lobe affect outcomes of robot-assisted laparoscopic radical prostatectomy? J Endourol 2012;26:264-70.

13. Huang AC, Kowalczyk KJ, Hevelone ND et al (2011) The impact of prostate size, median lobe, and prior benign prostatic hyperplasia intervention on robot-assisted laparoscopic prostatectomy: technique and outcomes. Eur Urol 59:595-603.

14. Jung H, Ngor E, Slezak JM, Chang A, Chien GW. Impact of median lobe anatomy: does its presence affect surgical margin rates during robot-assisted laparoscopic prostatectomy? J Endourol. 2012; 26: 457-60.

15. Deliveliotis C, Protogerou V, Alargof E, Varkarakis J. Radical prostatectomy: Bladder neck preservation and puboprostatic ligament sparing-effects on continence and positive margins. Urology 2002;60:855-8.

16. Selli C, De Antoni P, Moro U, et al. Role of bladder neck preservation in urinary continence following radical retropubic prostatectomy. Scand J Urol Nephrol 2004;38:32-7. 